\title{
Remote Sensing for Assessing Rhizoctonia Crown and Root Rot Severity in Sugar Beet
}

Gregory J. Reynolds, Department of Plant Pathology, University of California, Davis 95616; Carol E. Windels, Department of Plant Pathology and Northwest Research and Outreach Center and Ian V. MacRae, Department of Entomology and Northwest Research and Outreach Center, University of Minnesota, Crookston 56716; and Soizik Laguette, Department of Earth System Science and Policy, University of North Dakota, Grand Forks 58202

\begin{abstract}
Reynolds, G. J., Windels, C. E., MacRae, I. V., and Laguette, S. 2012. Remote sensing for assessing Rhizoctonia crown and root rot severity in sugar beet. Plant Dis. 96:497-505.

Rhizoctonia crown and root rot (RCRR), caused by Rhizoctonia solani AG-2-2, is an increasingly important disease of sugar beet in Minnesota and North Dakota. Disease ratings are based on subjective, visual estimates of root rot severity ( 0 -to- 7 scale, where $0=$ healthy and $7=$ $100 \%$ rotted, foliage dead). Remote sensing was evaluated as an alternative method to assess RCRR. Field plots of sugar beet were inoculated with $R$. solani AG 2-2 IIIB at different inoculum densities at the 10-leaf stage in 2008 and 2009. Data were collected for (i) hyperspectral reflectance from the sugar beet canopy and (ii) visual ratings of RCRR in 2008 at 2, 4, 6, and 8 weeks after inoculation (WAI) and in

2009 at 2, 3, 5, and 9 WAI. Green, red, and near-infrared reflectance and several calculated narrowband and wideband vegetation indices (VIs) were correlated with visual RCRR ratings, and all resulted in strong nonlinear regressions. Values of VIs were constant until at least 26 to $50 \%$ of the root surface was rotted (RCRR $=4$, wilting of foliage starting to develop) and then decreased significantly as RCRR ratings increased and plants began dying. RCRR also was detected using airborne, color-infrared imagery at 0.25 - and $1-\mathrm{m}$ resolution. Remote sensing can detect RCRR but not before initial appearance of foliar symptoms.
\end{abstract}

The soilborne fungus Rhizoctonia solani Kühn AG-2-2 intraspecific groups IIIB and IV cause Rhizoctonia crown and root rot (RCRR) of sugar beet (Beta vulgaris L.) $(11,73,74)$. Since the early 1990 s, these pathogens have become widespread in sugar beetgrowing regions of Minnesota and North Dakota because of wet weather (40), planting of susceptible sugar beet cultivars (Al Cattanach, personal communication), and increased production of soybean, edible bean, and corn (69), which are alternate hosts of $R$. solani AG-2-2 $(11,20,32,73,74)$. Production of these susceptible rotation crops in the sugar beet cropping system allows $R$. solani inoculum to build up in soil and contribute to disease outbreaks. Management of RCRR is achieved through rotations of three or more years with non-host plants $(57,58,75)$, early planting $(10)$, and application of fungicides $(22,27,28,67,72)$.

Symptoms of RCRR include a dark-brown to gray rot that typically begins near the crown and spreads over the root surface, eventually causing cracking and sunken lesions (75). Petioles are black and rotted at the point of attachment to the crown. Sometimes, infections occur on the root tip or laterally on the root surface (75). Aboveground, foliage may show sudden and severe wilting and then chlorosis; severely infected plants eventually die. Disease severity typically is assessed by a visual rating scale based on the amount of rot on the tap root (45). This rating system, however, is destructive and requires removal of roots from soil. Furthermore, visual disease assessments are subjective in nature and affected by fatigue, bias, human error, and differences in estimates among raters $(38,41,43,60,61)$.

Remote sensing is an alternative method to nondestructively assess plant diseases rapidly, repeatedly, and over a large area without physical contact with the sampling unit (i.e., sugar beet foliage; 38). Remote sensing in agriculture typically involves measuring

Corresponding author: G. J. Reynolds, E-mail: greynolds@ucdavis.edu

Accepted for publication 19 November 2011.

http://dx.doi.org/10.1094/PDIS-11-10-0831

(C) 2012 The American Phytopathological Society reflectance of electromagnetic radiation from the subject of interest (i.e., vegetation), usually in the visible (390 to $770 \mathrm{~nm}$ ), near-infrared (NIR, 770 to $1,300 \mathrm{~nm}$ ), or middle-infrared $(1,300$ to 2,500 $\mathrm{nm}$ ) ranges (23). The technology is advantageous because reflectance over broad electromagnetic domains may be measured in a nondestructive manner, over a wide area, and in real time (19).

Instruments may collect either hyperspectral or multispectral reflectance data. Hyperspectral sensors measure reflectance continuously as a series of narrow wavelength bands while multispectral sensors measure average reflectance at a few wide bands separated by segments where no measurements are taken (35). Both hyperspectral and multispectral reflectance data typically are converted to vegetation indices, where two or more important wavebands are mathematically combined to provide pertinent information on plant biophysical parameters (i.e., chlorophyll content) or to correct for background interference from soil or the atmosphere (68).

Extensive reviews on the application of remote sensing to detection of plant diseases have been written by Jackson (21), Hatfield and Pinter (17), Nilsson (38), and West et al. (71). Nutter et al. concluded from two studies that remote sensing-based disease assessments were more precise and accurate than visual disease assessments for Sclerotinia homeocarpa on bentgrass (41) and foliar diseases in alfalfa (42). The technology also has shown potential for detecting root stress and diseases in several crops $(9,13,44,47,70)$, including diseases caused by $R$. solani, such as rice sheath blight (48) and blight of creeping bentgrass (49). Remote sensing technology also has been applied to the detection of sugar beet diseases, including Cercospora leaf spot (65) and Rhizomania (66). Thus, there is potential for application of remote sensing to detect or assess RCRR.

Aboveground symptoms of RCRR (sudden, permanent wilting of leaves and yellowing of foliage) are the basis for remote detection of this disease. Using remote sensing technology, it also may be possible to detect stress in sugar beet plants before visible wilting occurs, because reduced photosynthesis rates or water content may produce subtle, detectable changes that would be invisible to the naked eye. Chavez et al. (6) detected Potato yellow vein virus in potato prior to the development of visible chlorosis using a remote sensing-based approach. Similarly, photosynthesis rates de- 
creased by as much as $14 \%$ in yellow poplar prior to development of visible ozone injury symptoms (14). Johnsen et al. (24) detected water stress in creeping bentgrass by remote sensing as much as 48 $\mathrm{h}$ before visible wilting occurred.

Laudien et al. $(30,31)$ conducted research to determine the potential for remote sensing to detect RCRR but focused only on the distinction between healthy and diseased plants near the end of the growing season. Early-season detection of the disease was not assessed, nor was the relationship of reflectance to severity of RCRR. Early detection of RCRR or the ability to assess disease severity based on remote sensing may allow for rapid assessment of entire fields.

The objectives of this study were to (i) investigate the potential for remote sensing in early detection of RCRR on sugar beet and (ii) identify optimal vegetation indices for correlating with visual disease severity ratings. A brief report has been published (53).

\section{Materials and Methods}

Field trials. Experiments were established at the University of Minnesota, Northwest Research and Outreach Center, Crookston, in 2008 and 2009. Both sites had been sown to soybean the previous year and were fertilized following standard procedure to maximize sugar beet yield and quality (26). In 2008, the field site ( 60 by $65.5 \mathrm{~m}$ ) was sown on 21 May with two nontransgenic commercial sugar beet cultivars: one susceptible ('Vanderhave 4653') and the other partially resistant ('Hilleshog 3035') to RCRR. In 2009, the site was slightly smaller (47 by $65.5 \mathrm{~m}$ ) because some 2008 Rhizoctonia inoculum density treatments resulted in similar disease severities. Roundup Ready cultivars were selected in 2009 because of the rapid adoption ( $88 \%$ hectares) of transgenic cultivars by sugar beet producers in Minnesota and North Dakota in 2009 (64). Plots were planted with 'Crystal 539RR' and 'Crystal 658RR' (partially resistant and susceptible to RCRR, respectively).

In both years, seed were sown every $4.76 \mathrm{~cm}$ at a depth of 2.5 $\mathrm{cm}$ in rows $0.56 \mathrm{~m}$ apart. In 2008, each treatment was assigned to six-row plots arranged in a two-by-eight factorial treatment design of four replicates; in 2009, a two-by-six factorial design was used. Each plot was $3.35 \mathrm{~m}$ wide by $10.7 \mathrm{~m}$ long, and blocks were separated by $7.6-\mathrm{m}$ alleys. Plant populations were thinned to $17.8-\mathrm{cm}$ spacing on 26 June 2008 and 18 June 2009. In both years, plots were treated with the insecticide terbufos (Counter; BASF, Ludwigshafen, Germany) at planting $\left(1.7 \mathrm{~kg}\right.$ a.i. $\left.\mathrm{ha}^{-1}\right)$ to control root insects. In 2009, chlorpyrifos (Lorsban-4E; Dow AgroSciences, Indianapolis, IN) also was applied postemergence $\left(0.84 \mathrm{~kg}\right.$ a.i. $\left.\mathrm{ha}^{-1}\right)$ because of higher than normal sugar beet root maggot populations. In 2008, microrate applications of the herbicides triflusulfuron (UpBeet, 236 to $710 \mathrm{ml}$ a.i. ha ${ }^{-1}$; DuPont, Wilmington, DE), desmedipham+phenmediphan (Betamix, $3.5 \mathrm{~g}$ a.i. ha ${ }^{-1}$; Bayer CropScience US, Pittsburgh), clopyralid (Stinger, 25 to $30 \mathrm{ml}$ a.i. $\mathrm{ha}^{-1}$; Dow AgroSciences), clethodim (Select, 70 to $130 \mathrm{ml}$ a.i. ha ${ }^{-1}$; Arysta LifeScience, Cary, NC), and methylated seed oil adjuvant (473 to $592 \mathrm{ml}$ a.i. ha ${ }^{-1}$ ) were made at four intervals, beginning on 15 June and continuing every 6 days. An additional application of desmedipham+phenmediphan and triflusulfuron $(947 \mathrm{ml}$ and $9.5 \mathrm{~g}$ a.i. ha $^{-1}$, respectively) was applied 10 days later. Weeds were controlled in 2009 with two applications of glyphosate (Roundup; Monsanto, Creve Coeur, MO) in mid-June and mid-July (1.7 and $2.2 \mathrm{~kg}$ a.i. $\mathrm{ha}^{-1}$, respectively). Application of glyphosate does not affect RCRR severity ratings in the field (2). Cercospora leaf spot (CLS) was controlled in 2008 by successive applications of triphenyl tin hydroxide (Super Tin, $0.35 \mathrm{~kg}$ a.i. ha ${ }^{-1}$; DuPont), tetraconazole (Eminent, $0.91 \mathrm{~kg}$ a.i. $\mathrm{ha}^{-1}$; Isagro-USA, Morrisville, $\mathrm{NC}$ ), and pyraclostrobin (Headline, $0.63 \mathrm{~kg}$ a.i. ha ${ }^{-1}$; BASF) from early August to early September. In 2009, only one fungicide application was necessary to control CLS, and pyraclostrobin was applied at $0.63 \mathrm{~kg}$ a.i. $\mathrm{ha}^{-1}$ in early September. Chemicals were applied with a tractor-mounted sprayer and TeeJet 8002 flat fan nozzles at $7.0 \mathrm{~kg} / \mathrm{cm}^{2}$.

Inoculation with $\boldsymbol{R}$. solani. Inoculum was prepared on corn kernels (10) and also on barley grain (56). For corn kernel inoculum, dent corn was soaked in distilled water for $12 \mathrm{~h}$ in 750-ml beakers, drained, and autoclaved at $121^{\circ} \mathrm{C}$ for $60 \mathrm{~min}$ on two consecutive days. $R$. solani AG-2-2 IIIB (isolate 87-36-4; 10) was grown on acidified potato-dextrose agar (APDA) for 7 days. Four $1.5-\mathrm{cm}-$ diameter disks from the margin of an actively growing colony were transferred to the corn kernels and incubated at $21 \pm 1^{\circ} \mathrm{C}$ for 21 to 38 days (containers were shaken every 2 days). Barley grain inoculum was prepared by combining $3,120 \mathrm{~cm}^{3}$ of barley and $1,800 \mathrm{ml}$ of distilled water in aluminum pans ( 30.5 by 50.8 by $10.2 \mathrm{~cm}$ ). Grain was autoclaved for $120 \mathrm{~min}$ on two consecutive days, inoculated with 151.5 -cm-diameter disks from the margin of 7-day-old cultures on APDA, and incubated at $21 \pm 1^{\circ} \mathrm{C}$ for 14 to 21 days. After $R$. solani had completely colonized barley grains, inoculum was dried for $36 \mathrm{~h}$ and ground in a Wiley Mill (number 3 roundhole screen, 3.2-mm mesh). Inoculum was stored at $21 \pm 1{ }^{\circ} \mathrm{C}$ in the laboratory for 3 weeks until used. Some corn kernels were cut in half with razor blades the day of inoculation to reduce inoculum density.

In both years, sugar beet plants were inoculated before closure of the row by foliage, at the 10- to 12-leaf stage. On 10 and 11 July 2008 , inoculum was applied to plots of each cultivar to attain a range of RCRR disease severities (4). Each cultivar was treated with seven different inoculum densities in separate plots, and each density was applied to all plants in the center four rows of six-row plots. Treatments included either corn kernel inoculum (at one-half or two R. solani-infested kernels per root) or ground barley inoculum at five different rates $(1.5,2.2,3,3.7$, or $4.5 \mathrm{~g} / \mathrm{m}$ of row). Plants were inoculated with corn kernel inoculum by removing soil from the root about $2.5 \mathrm{~cm}$ below the soil surface, placing inoculum adjacent to the exposed tap root, and re-covering with soil. Ground barley inoculum was deposited in sugar beet crowns with a Gandy granule applicator calibrated to release appropriate rates per meter of row (56). Control plots were not inoculated. Plots then were cultivated to throw soil into crowns and cover inoculum to favor infections (56). In 2009, plots were inoculated on 6 July as previously described but the 2.2- and 3.7-g rates of barley inoculum were not used because they were not needed to attain a range of disease severities based on results from 2008. Plots were not irrigated, but, within 1 week after inoculation, $1.88 \mathrm{~cm}$ of precipitation occurred in 2008 and $3.96 \mathrm{~cm}$ in 2009.

Spectral and disease assessments. To correlate spectral measurements and disease severity, each plot was divided by a flag that marked a $6.1-\mathrm{m}$ length for measuring spectral reflectance and the remaining $4.6 \mathrm{~m}$ for removal of plants to visually rate RCRR severity. This allowed for multiple spectral reflectance measurements of a full sugar beet canopy, as well as destructive removal of roots. Previous research has shown that RCRR ratings on half a research plot are the same as across the whole plot (4). Furthermore, aboveground symptoms in the portion rated for disease were consistent with those in the portion measured spectrally. Reflectance and disease severity were measured on the same day. In 2008, data were collected on 25 July, 7 and 18 August, and 3 September at 2, 4,6 , and 8 weeks after inoculation, respectively. In 2009, data were collected on 21 and 28 July, 11 August, and 9 September at 2, 3, 5, and 9 weeks after inoculation, respectively. Assessments were not obtained at equal intervals in both years because clouds were a limiting factor; clear skies were required for the spectral measurements.

Reflectance data were acquired with a FieldSpec FR hand-held spectroradiometer (Analytical Spectral Devices, Inc.; Boulder, $\mathrm{CO}$ ), which is composed of three separate spectrometers in the same enclosure. It has a sampling interval of $1.4 \mathrm{~nm}$ for the $350-$ to $1,000-\mathrm{nm}$ region of the electromagnetic spectrum (3-nm spectral resolution) and $2 \mathrm{~nm}$ for the 1,000- to 2,500-nm region $(10-\mathrm{nm}$ spectral resolution), with a field of view of $25^{\circ}$. Three data measurements were collected $1.2 \mathrm{~m}$ from the top of the sugar beet canopy at nadir, meaning the instrument is directed downward in line with gravity and diametrically opposed to the zenith; this provided a 50.8-cm-diameter field of view. Measurements were taken on clear, sunny days between 10:00 a.m. and 2:00 p.m. CST to ensure 
consistent sun angle and intensity for all plots and all assessment dates (16) and obtained at 2-m intervals within the 6.1-m spectral measurement portion of each plot, at least $1 \mathrm{~m}$ from plot edges. The instrument was optimized with a calibrated spectralon white reflectance panel every $15 \mathrm{~min}$ while readings were obtained, allowing readings from different assessment dates to be compared. The panel reflects close to $100 \%$ of all incident radiation, and reflectance values are calculated as a ratio of reflected radiation to incident radiation.

At each sampling date, 10 plants were arbitrarily removed from the four middle rows of the 4.6-m section of each plot not used for spectral assessment (two or three plants per row evenly distributed throughout the area). Because every plant in the four 10.7-m-length rows was inoculated per plot, variability in disease ratings was minimized among plants within the same plot. About $30 \%$ of plants in the sampled area were removed by the end of the season, and previous studies indicated that this proportion of sampling was representative of the plot (4). Tap roots were visually assessed for RCRR using a 0 -to-7 scale (45), where $0=$ no visible lesions; $1=$ superficial, scattered inactive lesions; $2=$ shallow, dry rot cankers or active lesions on $\leq 5 \%$ of root surface; $3=$ deep dry-rot cankers at crown or extensive lateral lesions affecting 6 to $25 \%$ of the root; $4=$ rot affecting 26 to $50 \%$ of tap root, with cracks and cankers up to $5 \mathrm{~mm}$ deep; $5=51$ to $75 \%$ of tap root blackened, with rot extending into interior and roots usually misshapen with cracks and rifts; $6=$ entire root blackened except extreme tip; and $7=$ root $100 \%$ rotted and foliage dead. Ratings of the 10 beet plants were averaged to estimate the overall plot RCRR severity per sampling date. This rating scale is discontinuous because it is more difficult to assess small changes in severity at moderate levels of disease than at very high or very low levels of disease (18), especially on tap roots. The rating scale, however, is well established, and continuous data assessment scales have not been developed for RCRR.

Aerial imagery. To validate the 2 years of ground-based remote sensing data, aerial, color-infrared (CIR) digital imagery of the 2009 field trial was obtained using the Airborne Environmental Research Observational Camera (AEROcam, Upper Midwest Aerospace Consortium, University of North Dakota, Grand Forks), an MS4100 High Resolution 3-CCD Digital Multispectral Camera (Geospatial Systems Incorporated, Rochester, NY). This camera measures reflectance in three bands that approximate Landsat satellite bands: green $(520$ to $600 \mathrm{~nm})$, red $(630$ to $690 \mathrm{~nm})$, and NIR (760 to $900 \mathrm{~nm}$ ). The camera was mounted on a Piper Arrow PA28-201; imagery was acquired at $457.2 \mathrm{~m}$ above ground level (AGL; $0.25-\mathrm{m}$ pixel size) on three dates, each within 2 days of ground-based spectral measurements and disease assessments (3, 5 , and 9 weeks after inoculation). One set of imagery also was acquired from 1,829 m AGL (1-m pixel size) on 6 August 2009. Global positioning system (GPS) coordinates were obtained at corners of the four blocks of the field trial as well as at corners of neighboring fields with an AgGPS 132 (Trimble Navigation Limited, Sunnyvale, CA) submeter, differentially corrected GPS with combined L1, satellite, and beacon antenna for georeferencing. Control point error for rectification of the $0.25-\mathrm{m}$ spatial resolution CIR digital imagery was 0.0164 pixels on 28 July, 0.0134 pixels on 13 August, and 0.0146 pixels on 9 September 2009.

Aerial CIR digital images were processed using ERDAS Imagine (version 9.3; ERDAS, Inc., Atlanta, GA). The images were cropped to include only the field trial to reduce processing time. The GPS coordinates at block and field corners were used to georeference and geometrically rectify the images. Maps then were generated by calculating the optimized soil-adjusted vegetation index (OSAVI; Table 1) (54) for each pixel. OSAVI is a vegetation index ranging from 0 to 1 that incorporates red and NIR reflectance with a universal soil transformation (0.16). It was selected because it is a common multispectral vegetation index associated with chlorophyll content that showed promise in both the 2008 ground-based results (53) and in preliminary research by Laudien et al. (31). The ground-based spectral measurements and disease assessments were used as ground truth data (on location information collected to relate remote sensing measurements to real features on the ground).

Statistical analyses. Hyperspectral reflectance signatures were compared visually using ViewSpecPro (Analytical Spectral Devices, Inc.). First derivatives also were calculated and visually compared using this software to qualitatively identify pertinent wavelengths associated with RCRR infection. To identify optimal indices for assessing RCRR severity, hyperspectral reflectance data were combined into various narrowband and wideband vegetation indices associated with chlorophyll or water content (Table 1). Vegetation index values were regressed against disease severity values using regression analysis in $\mathrm{R}$, version 2.10 .1 (50). Linear regression models were initially tested with data from the susceptible and partially resistant cultivars combined, but, because cultivars showed significant differences in 2009 for most indices assessed, each cultivar was ultimately assessed individually. $P$ values showing the differences between cultivars were obtained from these initial, combined linear regression models. Because relationships between vegetation indices and disease severity frequently were nonlinear, regressions of increasingly higher order also were assessed to determine the best fit model. Significant $P$ values $(\leq 0.05)$ for all coefficients were required of higher-order models for a nonlinear model to be selected. When nonlinear models were selected, a tipping point (where the vegetation index begins to descend) was visually identified where index values begin to change. To assess the difference in RCRR ratings between cultivars, analysis of covariance (ANCOVA) was used to compare disease ratings from control and barley-inoculated plots using inoculum dosage as the continuous variable and cultivar as the categorical variable. Corn inoculum treatments were not included because they were not continuous with barley inoculum dosages.

\section{Results}

Disease development. A wide range of disease ratings for RCRR was obtained across plots at each assessment date (Table 2). In each plot, disease symptoms developed uniformly in the portions used to rate roots for disease and for spectral measurements throughout the growing season. In both years, the range of inoculum density treatments resulted in various times for onset of belowground (Table 2) and aboveground symptoms of RCRR, which was ideal for monitoring disease development by spectral

Table 1. Reflectance ranges and vegetation indices assessed for correlation with Rhizoctonia crown and root rot disease ratings from sugar beet plots at the University of Minnesota, Northwest Research and Outreach Center, Crookston

\begin{tabular}{llc}
\hline Index $^{\mathrm{a}}$ & \multicolumn{1}{c}{ Formula $^{\mathbf{b}}$} & Reference \\
\hline Green & $R_{548-563}$ & $\ldots$ \\
Red & $R_{668-683}$ & $\ldots$ \\
NIR & $R_{898-913}$ & $\ldots$ \\
DVI & NIR - Red & 25 \\
SRVI & NIR/Red & 70 \\
NDVI & $(\mathrm{NIR}-\mathrm{Red}) /(\mathrm{NIR}+\mathrm{Red})$ & 55 \\
OSAVI & $(\mathrm{NIR}-\mathrm{Red}) /(\mathrm{NIR}+\mathrm{Red}+0.16)$ & 54 \\
GNDVI & $(\mathrm{NIR}-\mathrm{Green}) /(\mathrm{NIR}+\mathrm{Green})$ & 15 \\
PSSR & $R_{800} / R_{680}$ & 3 \\
PSSR & $R_{800} / R_{635}$ & 3 \\
RVSI & $\left(R_{714}+R_{752}\right) / 2-R_{733}$ & 36 \\
LWI & $\left.R_{1300} / R_{1450}\right) /\left(R_{705}+R_{455}\right)$ & 59 \\
mSR & $\left(R_{750}-R_{445}\right) /\left(R_{790}+R_{720}\right)$ & 62 \\
NDRE & $\left(R_{790}-R_{720}\right)$ & 1 \\
\hline
\end{tabular}

${ }^{\text {a }}$ Green $=$ green reflectance, Red $=$ red reflectance, NIR $=$ near-infrared reflectance, DVI $=$ difference vegetation index, SRVI $=$ simple ratio vegetation index, NDVI = normalized difference vegetation index, OSAVI $=$ optimized soil-adjusted vegetation index, GNDVI = green normalized difference vegetation index, $\operatorname{PSSR}_{\mathrm{a}}=$ pigment specific simple ratio $\left(\right.$ chlorophyll- $a$ ), PSSR $_{\mathrm{b}}=$ pigment specific simple ratio (chlorophyll- $b$ ), RVSI $=$ red edge vegetation stress index, LWI $=$ leaf water index, $\mathrm{mSR}=$ modified spectral ratio, and NDRE = normalized difference red edge.

${ }^{\mathrm{b}} R$ represents reflectance at the given wavelength or wavelength range (nm). 
measurements. Root symptoms of RCRR developed first, and aboveground symptoms of wilt were observed when ratings reached a value of 4 ( 26 to $50 \%$ of the root surface rotted). Chlorosis developed as RCRR values increased.

At 2 weeks after inoculation in both years, some plants in plots with high inoculum densities (one-half and two corn kernels per root) were beginning to wilt but no chlorosis was observed; these symptomatic plants also had darkened petioles at the soil line. At this time, the other inoculated plots and noninoculated controls displayed no aboveground symptoms of RCRR, although root rot was beginning to develop (Table 2). Plots inoculated with $R$. solani-infested corn kernels (both rates) had RCRR ratings $>4$ by the next sampling date, and most were extensively wilted and chlorotic. In 2008, plots inoculated with the lowest density of $R$. solani (infested grain at $1.5 \mathrm{~g} / \mathrm{m}$ of row) had low RCRR values and did not develop chlorosis or wilting during the growing season; in 2009, disease was more severe and RCRR values resulted in aboveground symptoms by 9 weeks after inoculation. By comparison, the moderate to high rates of infested barley grain inoculum $(2.2,3,3.7$, and $4.5 \mathrm{~g} / \mathrm{m})$ often resulted in higher RCRR ratings (Table 2) and earlier development of aboveground symptoms after inoculation compared with the 1.5 -g rate.

In both years, ratings for RCRR consistently were higher for both cultivars at all assessment dates when inoculum levels were high (one-half or two infested corn kernels per root) and usually were lower for the partially resistant than susceptible cultivar for all rates of barley grain inoculum (Table 2). In 2008, ANCOVA showed a significant effect of cultivar on RCRR ratings ( $P$ value $<$ 0.0001 ), with the susceptible cultivar developing increasingly more severe RCRR ratings than the partially resistant cultivar as inoculum dose increased. In 2009, the effect of cultivar was somewhat significant $(P$ value $=0.0944)$, with the susceptible cultivar having slightly higher RCRR ratings overall than the partially resistant cultivar.

Spectral measurements. Several wavelengths were identified through first derivative analysis as being associated with RCRR severity, including some in the red $(660$ and $680 \mathrm{~nm})$, red-edge (730 and $740 \mathrm{~nm})$, and $\mathrm{NIR}(1,130,1,145$, and 1,330 $\mathrm{nm}$ ) ranges; all of these bands, or close approximations, are incorporated into one or more of the vegetation indices assessed (Table 3). Visual inspection of hyperspectral reflectance signatures for healthy and RCRR-diseased plots showed that wilting and chlorotic sugar beet plot canopies were associated with increased red and red-edge reflectance $(620$ to $750 \mathrm{~nm}$ ), decreased NIR reflectance (770 to
$1300 \mathrm{~nm})$, and increased middle-infrared reflectance $(1,300$ to $2,500 \mathrm{~nm}$ ) (data not shown). Reflectance signatures of plots with maximum RCRR severity (disease rating $=7$, where root is completely rotted and foliage dead) were closely associated with the reflectance signatures of bare soil measured in alleys.

Although cultivars responded to RCRR infection similarly in 2008, the partially resistant and susceptible cultivars had significantly different responses in 2009; therefore, cultivars were assessed individually each year. Reflectance in the red and NIR ranges and all vegetation indices assessed yielded statistically significant regression models when plotted against disease ratings for RCRR of both cultivars in 2008 and 2009 ( $P<0.0001$; Table 3$)$. Many of these indices also had $R^{2}$ values higher than 0.6 , meaning the index in question accounts for over $60 \%$ of the variability in the data. Because the relationships between disease severity and many of the indices were nonlinear, higher-order models also were assessed. Models selected were linear, second-order, or third-order. Green reflectance was the only variable assessed that did not consistently have significant $P$ values for both cultivars in both years (Table 3).

Because $P$ values and $R^{2}$ values were comparable for most reflectance ranges and vegetation indices tested, no single vegetation index was optimal. The OSAVI consistently had the highest or second highest $R^{2}$ value of indices assessed and was selected as representative of the wideband indices (Fig. 1). Other wideband index values followed the same relationship to RCRR as OSAVI (data not shown).

In both years, OSAVI values generally were constant at RCRR disease ratings of 0 until about 5 (when extensive rot, cracks, and cankers affect more than $50 \%$ of the root surface) in the susceptible (Fig. 1A and C) and partially resistant (Fig. 1B and D) cultivars; then, index values dropped as RCRR severity increased. Early foliar symptoms of wilting and chlorosis were not observed in cultivars until RCRR reached values around 4. In 2008, the relationship between OSAVI and RCRR values was similar for both cultivars; disease was detected somewhat earlier in the partially resistant (Fig. 1B) than in the susceptible cultivar (Fig. 1A) but the difference was not statistically significant $(P$ value $=$ 0.3070). The "tipping point" (when vegetation index values began to descend) was at a disease rating of around 5 for the susceptible cultivar (Fig. 1A) and around 4 for the partially resistant cultivar (Fig. 1B). In 2009, the susceptible and partially resistant cultivars yielded significantly different OSAVI responses to RCRR ( $P$ value $=0.0019)$, most likely due to differences in the y-intercept coeffi-

Table 2. Development of Rhizoctonia crown and root rot (RCRR) several weeks after inoculating the upper $2.5 \mathrm{~cm}$ of sugar beet roots with different numbers of $R$. solani-infested corn kernels or inoculating crowns with various rates of infested ground barley inoculum when plants were at the 10- to 12-leaf stage in two growing seasons

\begin{tabular}{|c|c|c|c|c|c|c|c|c|c|c|c|c|c|c|c|c|}
\hline \multirow[b]{4}{*}{ Year, WAI ${ }^{\mathrm{b}}$} & \multicolumn{16}{|c|}{ Average rating for RCRR (0-to-7 scale) ${ }^{\mathrm{a}}$} \\
\hline & & & Nun & $\mathrm{rof} c$ & kern & root & & & Amot & of $\mathrm{gr}$ & d bar & inoce & $n(g / n$ & f row) & & \\
\hline & \multicolumn{2}{|c|}{ Control } & \multicolumn{2}{|c|}{$1 / 2$} & \multicolumn{2}{|c|}{2} & \multicolumn{2}{|c|}{1.5} & \multicolumn{2}{|c|}{2.2} & \multicolumn{2}{|c|}{3} & \multicolumn{2}{|c|}{3.7} & \multicolumn{2}{|c|}{4.5} \\
\hline & PR & $\mathbf{S}$ & PR & $\mathbf{S}$ & PR & $\mathbf{S}$ & PR & $\mathbf{S}$ & PR & $\mathbf{S}$ & PR & $\mathbf{S}$ & $\mathbf{P R}$ & $\mathbf{S}$ & PR & $\mathbf{S}$ \\
\hline \multicolumn{17}{|l|}{2008} \\
\hline 2 & 0.6 & 0.5 & 3.2 & 3.6 & 3.3 & 4.1 & 1.7 & 1.5 & 1.7 & 2.1 & 2.2 & 1.9 & 2.0 & 2.6 & 2.2 & 2.2 \\
\hline 4 & 1.3 & 0.9 & 4.5 & 5.6 & 6.0 & 6.9 & 1.5 & 2.5 & 1.8 & 2.4 & 2.3 & 2.7 & 2.2 & 4.0 & 2.1 & 3.3 \\
\hline 6 & 1.6 & 1.2 & 5.0 & 6.5 & 6.7 & 7.0 & 1.9 & 3.0 & 2.2 & 3.4 & 2.3 & 3.5 & 3.0 & 4.8 & 2.9 & 3.9 \\
\hline 8 & 1.2 & 1.0 & 5.2 & 6.3 & 6.5 & 7.0 & 1.7 & 2.5 & 2.5 & 3.1 & 3.1 & 3.4 & 2.3 & 6.2 & 3.2 & 4.6 \\
\hline \multicolumn{17}{|l|}{2009} \\
\hline 2 & 1.1 & 0.9 & 3.4 & 3.8 & 4.1 & 4.5 & 1.7 & 1.9 & - & - & 2.5 & 2.0 & - & - & 2.3 & 2.5 \\
\hline 3 & 1.1 & 1.1 & 4.1 & 4.5 & 4.3 & 5.2 & 1.7 & 2.4 & - & - & 3.2 & 3.0 & _- & - & 3.3 & 3.7 \\
\hline 5 & 1.1 & 1.5 & 5.0 & 5.8 & 5.9 & 6.5 & 2.5 & 3.9 & - & - & 4.3 & 4.6 & - & - & 4.5 & 5.1 \\
\hline 9 & 1.5 & 1.9 & 5.7 & 6.7 & 6.5 & 7.0 & 4.0 & 6.0 & - & - & 5.8 & 6.2 & - & - & 5.9 & 6.5 \\
\hline
\end{tabular}

${ }^{\text {a }}$ Scale where $0=$ no visible lesions on root and $7=$ root $100 \%$ rotted and foliage dead (45); each value is based on an average of 10 roots per plot, four replicates. Plots were inoculated on 10 and 11 July 2008 and 6 July 2009 when foliage was in the 10- to 12-leaf stage; - = not inoculated. Rhizoctonia solani-infested corn kernels were placed on the root surface about $2.5 \mathrm{~cm}$ below the soil line (10); various rates of infested, ground barley inoculum were applied into crowns with a Gandy applicator (56). All plants in the four center rows of six-row plots were inoculated per treatment; control plots were not inoculated. PR = partially resistant ('Hilleshog 3035' in 2008 and 'Crystal 539RR' in 2009) and S = susceptible ('VanderHave 4653' in 2008 and 'Crystal 658RR' in 2009).

${ }^{\mathrm{b}} \mathrm{WAI}=$ weeks after inoculation. 
cient and higher overall OSAVI values with the partially resistant (Fig. 1D) compared with the susceptible (Fig. 1C) cultivar. The tipping point occurred in the OSAVI at RCRR ratings of about 5 for both cultivars in 2009 (Fig. 1C and D).

The modified spectral ratio (mSR; Table $1 ; 62)$, selected as representative of the narrowband indices, allowed for earlier detection of RCRR (Fig. 2) than the OSAVI (Fig. 1) but was more variable. The mSR values were constant at RCRR disease ratings of 0 to 3 , when foliage appeared healthy and 6 to $25 \%$ of the root surface was rotted; then, mSR values decreased as disease severity increased. In 2008, the susceptible (Fig. 2A) and partially resistant (Fig. 2B) cultivars followed the same trends $(P$ value $=0.1320)$. In 2009, the susceptible and partially resistant cultivars yielded significantly different $\mathrm{mSR}$ responses to RCRR $(P$ value $<0.0001)$, with the partially resistant cultivar (Fig. 2D) having higher overall index values than the susceptible cultivar (Fig. 2C). Changes in the mSR generally occurred at the onset of mild wilting. The tipping point occurred in the mSR at RCRR ratings of around 3.5 for both cultivars in both years (Fig. 2).

Aerial imagery. One typical block (replicate) of the field trial is shown at 3,5, and 9 weeks after inoculation (Fig. 3A). At each evaluation date, the filtered area (Fig. 3A, noted on the right side of the image) covers the portion of plots where roots were removed for disease assessment; the unfiltered area on the left was used for reflectance measurements. Ratings for RCRR from selected plots are provided as examples at each assessment date and include the two cultivars (susceptible [S] and partially resistant [PR]) inoculated with two $R$. solani-infested corn kernels (2k) and the noninoculated control (C). There was a low level of natural infestation by $R$. solani AG 2-2 in the trial area. Because of the infrared filter used on the camera, healthy vegetation is displayed as red; soil is cyan or black, depending on moisture; and dead foliage also appears cyan. Pixels from plots infected with RCRR range in appear- ance from red (healthy plants and plants with early root rot and no foliar symptoms), to varying mixtures of red and cyan (healthy plants and plants with root rot and foliar symptoms), to cyan (severely diseased, completely dead plants). As plants wilt, more background soil is exposed, causing part of the shift from red to cyan; dead foliage may also be contributing to the change. It was difficult to differentiate soil from dead sugar beet foliage except when soil moisture was very high and the soil appeared much darker than dead foliage. Severely diseased plots are indistinguishable from bare soil, validating the reflectance signatures obtained from the ground where plots with the maximum RCRR severity rating of seven had almost the same signature as bare soil.

Using CIR digital imagery (Fig. 3A), small patches of RCRR were identified in inoculated plots as early as 3 weeks after inoculation (WAI); some infected plants were evident in plots with RCRR severity ratings as low as 3.8 but RCRR infections only were consistently apparent in plots with increasingly higher RCRR severity ratings. Disease severity increased in prevalence and severity by 5 WAI and again by 9 WAI.

The OSAVI (Fig. 3B) was used to calculate a value for each pixel from the images of the same plots as those shown in Figure 3A. Again, the area visually rated for disease is shown on the right in a dark strip, and the area used for reflectance measurements is on the left side of each plot. The OSAVI values range from 0 to 1 , with 0 represented as black and 1 represented as white; values between 0 and 1 are shades of gray based on this continuum. Bare soil and chlorotic or necrotic vegetation have low OSAVI values and appear very dark, while healthy vegetation has a high OSAVI value and appears very light. From 3 to 9 WAI, OSAVI values calculated from canopy reflectance decreased in inoculated plots.

The aerial imagery (Fig. 3A) and derived OSAVI maps (Fig. 3B) are very similar in illustrating the detection and development of RCRR from 3 to 9 WAI. Furthermore, both images validated data

Table 3. Regression statistics for relationship between reflectance ranges and vegetation indices for root disease severity ratings of Rhizoctonia crown and root rot (RCRR) on sugar beet at the University of Minnesota, Northwest Research and Outreach Center, Crookston ${ }^{\mathrm{a}}$

\begin{tabular}{|c|c|c|c|c|c|c|c|}
\hline \multirow[b]{2}{*}{ Index $^{b}$} & \multirow[b]{2}{*}{ Cultivar $^{c}$} & \multicolumn{3}{|c|}{2008} & \multicolumn{3}{|c|}{2009} \\
\hline & & Order & $R^{2}$ & $P$ value & Order & $R^{2}$ & $P$ value \\
\hline \multirow[t]{2}{*}{ Green } & $\mathrm{S}$ & Linear & 0.002 & 0.6095 & Linear & 0.044 & $0.0392 *$ \\
\hline & PR & Linear & 0.072 & $0.0051 *$ & Linear & 0.056 & $0.0203 *$ \\
\hline \multirow[t]{2}{*}{ Red } & $\mathrm{S}$ & Second & 0.638 & $<0.0001 *$ & Second & 0.625 & $<0.0001 *$ \\
\hline & PR & Second & 0.618 & $<0.0001 *$ & Second & 0.459 & $<0.0001 *$ \\
\hline \multirow[t]{2}{*}{ NIR } & $\mathrm{S}$ & Third & 0.701 & $<0.0001 *$ & Linear & 0.521 & $<0.0001 *$ \\
\hline & PR & Second & 0.558 & $<0.0001 *$ & Linear & 0.351 & $<0.0001 *$ \\
\hline \multirow[t]{2}{*}{ DVI } & $\mathrm{S}$ & Third & 0.770 & $<0.0001 *$ & Third & 0.691 & $<0.0001 *$ \\
\hline & PR & Second & 0.651 & $<0.0001 *$ & Third & 0.556 & $<0.0001 *$ \\
\hline \multirow[t]{2}{*}{ SRVI } & $\mathrm{S}$ & Linear & 0.552 & $<0.0001 *$ & Linear & 0.582 & $<0.0001 *$ \\
\hline & PR & Second & 0.709 & $<0.0001^{*}$ & Linear & 0.409 & $<0.0001^{*}$ \\
\hline \multirow[t]{2}{*}{ NDVI } & $\mathrm{S}$ & Third & 0.858 & $<0.0001 *$ & Third & 0.760 & $<0.0001^{*}$ \\
\hline & PR & Second & 0.753 & $<0.0001^{*}$ & Third & 0.637 & $<0.0001^{*}$ \\
\hline \multirow[t]{2}{*}{ OSAVI } & $\mathrm{S}$ & Third & 0.856 & $<0.0001 *$ & Third & 0.762 & $<0.0001 *$ \\
\hline & PR & Second & 0.766 & $<0.0001^{*}$ & Third & 0.662 & $<0.0001^{*}$ \\
\hline \multirow[t]{2}{*}{ GNDVI } & $\mathrm{S}$ & Second & 0.732 & $<0.0001^{*}$ & Second & 0.641 & $<0.0001^{*}$ \\
\hline & PR & Second & 0.693 & $<0.0001^{*}$ & Second & 0.584 & $<0.0001 *$ \\
\hline \multirow{2}{*}{$\operatorname{PSSR}_{\mathrm{a}}$} & $\mathrm{S}$ & Linear & 0.553 & $<0.0001^{*}$ & Linear & 0.584 & $<0.0001^{*}$ \\
\hline & PR & Second & 0.713 & $<0.0001 *$ & Linear & 0.411 & $<0.0001^{*}$ \\
\hline \multirow[t]{2}{*}{$\mathrm{PSSR}_{\mathrm{b}}$} & $\mathrm{S}$ & Linear & 0.545 & $<0.0001 *$ & Linear & 0.576 & $<0.0001 *$ \\
\hline & PR & Second & 0.687 & $<0.0001 *$ & Linear & 0.471 & $<0.0001^{*}$ \\
\hline \multirow[t]{2}{*}{ RVSI } & $S$ & Third & 0.828 & $<0.0001 *$ & Second & 0.717 & $<0.0001 *$ \\
\hline & PR & Second & 0.667 & $<0.0001 *$ & Third & 0.554 & $<0.0001^{*}$ \\
\hline \multirow[t]{2}{*}{ LWI } & $\mathrm{S}$ & Linear & 0.558 & $<0.0001 *$ & Linear & 0.524 & $<0.0001 *$ \\
\hline & PR & Second & 0.624 & $<0.0001 *$ & Linear & 0.256 & $<0.0001^{*}$ \\
\hline \multirow[t]{2}{*}{$\mathrm{mSR}$} & $\mathrm{S}$ & Second & 0.689 & $<0.0001 *$ & Second & 0.671 & $<0.0001^{*}$ \\
\hline & PR & Second & 0.708 & $<0.0001^{*}$ & Second & 0.585 & $<0.0001^{*}$ \\
\hline \multirow[t]{2}{*}{ NDRE } & $\mathrm{S}$ & Second & 0.680 & $<0.0001 *$ & Second & 0.657 & $<0.0001 *$ \\
\hline & PR & Second & 0.627 & $<0.0001 *$ & Second & 0.631 & $<0.0001^{*}$ \\
\hline
\end{tabular}

a Asterisk (*) denotes statistical significance at $P$ values $<0.05$.

b Green $=$ green reflectance, Red $=$ red reflectance, NIR = near-infrared reflectance, DVI $=$ difference vegetation index, SRVI $=$ simple ratio vegetation index, NDVI = normalized difference vegetation index, OSAVI = optimized soil-adjusted vegetation index, GNDVI = green normalized difference vegetation index, PSSR $_{\mathrm{a}}=$ pigment specific simple ratio (chlorophyll- $a$ ), PSSR $_{\mathrm{b}}=$ pigment specific simple ratio $($ chlorophyll- $b$ ), RVSI $=$ red edge vegetation stress index, $\mathrm{LWI}=$ leaf water index, $\mathrm{mSR}=$ modified spectral ratio, and NDRE = normalized difference red edge.

c $\mathrm{S}=$ cultivar is susceptible to RCRR and PR = cultivar is partially resistant to RCRR. 
obtained from the ground, which showed that OSAVI values decreased after RCRR severity values reached a rating of 5 and foliar symptoms of wilting and chlorosis developed (Fig. 1).

\section{Discussion}

Vegetation indices did not consistently detect RCRR until root ratings indicated that 25 to $50 \%$ of the root surface was rotted $(\mathrm{RCRR}=4)$ and foliar symptoms of wilt were beginning to occur, making remote sensing based-assessment of RCRR most suitable for late-season use after infections have developed. This agrees with previous work on other crops with various pathogens, where root disease was not detected until visible foliar symptoms developed. For instance, Phytophthora root rot in cranberry was most consistently detected in late-season aerial imagery (47), and takeall of wheat was detected during the milk stage of grain development using a normalized difference vegetation index (7). In our research, no single narrowband or wideband index stood out as superior for correlation with RCRR disease severity ratings, likely because many of the indices assessed were based on similar wavelengths and associated with similar biophysical parameters (primarily chlorophyll content). Also, differences in $R^{2}$ values were negligible and most likely due to the number of wavelengths and width of the bands used to calculate each index. All wideband indices had better overall fits with RCRR severity than the narrowband indices because they incorporated two 15-nm-wide bands. Most of the narrowband indices incorporate two 1-nm wavebands and had wide variability, while the mSR incorporates three and had the lowest variability among narrowband indices. Although averages of the red, green, and NIR ranges were assessed, individual narrow wavebands were not tested because we wanted the data to be tied to our multispectral aerial imagery. Our goal was to eventually develop a tool useful for growers and sugar companies to rapidly assess large geographic areas for RCRR. Using individual narrow bands would assume that they will have access to hyperspectral imagery, which can be quite expensive.
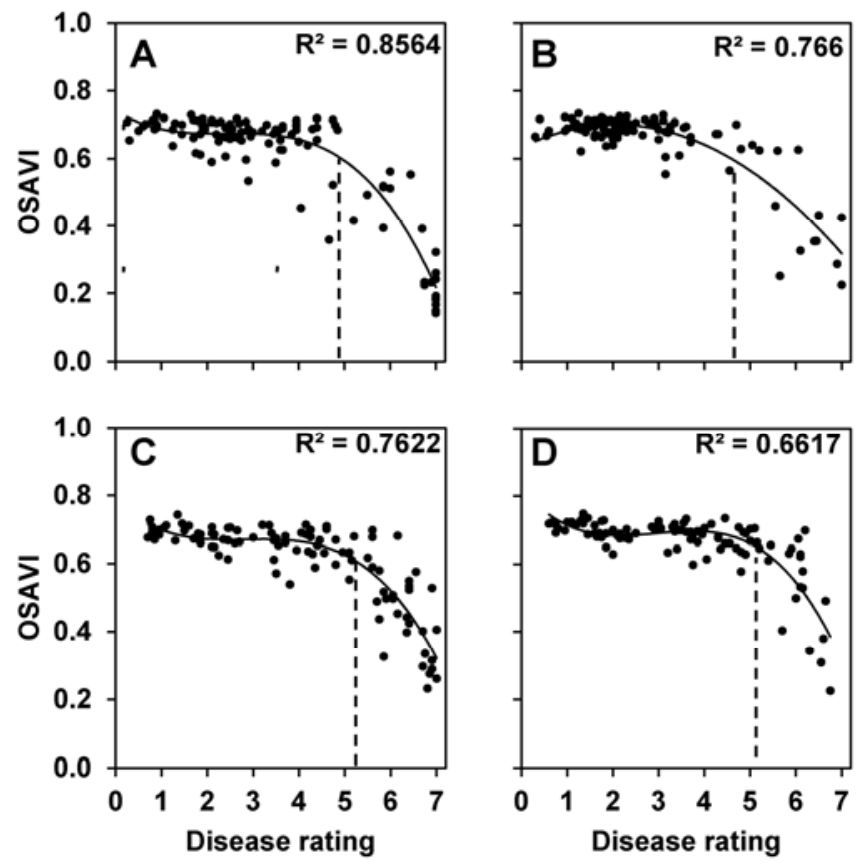

Fig. 1. Optimized soil-adjusted vegetation index (OSAVI) values plotted against Rhizoctonia crown and root rot (RCRR) disease ratings for $\mathbf{A}$, a susceptible (S) cultivar in $2008\left(y=-0.005 x^{3}+0.035 x^{2}-0.085 x+0.741\right)$; $\mathbf{B}$, a partially resistant (PR) cultivar in $2008\left(y=-0.016 x^{2}+0.065 x+0.633\right)$; C, an S cultivar in $2009(y=$ $\left.-0.005 x^{3}+0.043 x^{2}-0.12 x+0.78\right)$; and $D$, a PR cultivar in $2009\left(y=-0.006 x^{3}+\right.$ $0.057 x^{2}-0.156 x+0.82$ ) from field trials at the University of Minnesota, Northwest Research and Outreach Center, Crookston. Ratings for RCRR range from 0 to 7 and are based on the amount of rot present on sugar beet tap roots, where $0=$ healthy and $7=100 \%$ rotted and foliage is dead (45). "Tipping points", where OSAVI values begin to decline, were visually identified and are indicated by dashed lines.
The OSAVI and mSR indices correlated well with severity of RCRR, and both are associated with chlorophyll content, which is consistent with the chlorosis commonly associated with infected plants (75). Reduced chlorophyll content has been measured in root rots caused by Phytophthora spp. in citrus (34) and R. solani in broad bean (39), as well as in R. solani sheath blight in rice (37). In our research, vegetation indices associated with water content (i.e., leaf water index) also had similar patterns when plotted against RCRR disease severity values. Thus, it is unclear if changes in the vegetation indices observed with higher disease severity ratings were associated with reduction in chlorophyll content (which appeared to occur after wilting) or with increased soil background reflectance and reduced moisture. The close association between reflectance in plots with high disease severity and bare soil reflectance may indicate that changes in all vegetation indices were influenced by increased soil reflectance due to a wilting canopy. However, changes in some vegetation indices occurred at the onset of visible wilting, when foliage still covered most of the soil background. Thus, changing canopy structure due to wilting also likely plays a major role in the early changes observed. Reflectance in the NIR is heavily affected by leaf angle and canopy geometry (33). Most of the vegetation indices assessed in our research incorporate an NIR band. Because wilting was the first visible foliar symptom to occur, early changes in these indices are probably due to changes in canopy structure.

At the canopy level, spectral responses are influenced by three main factors: physiological state of the plants, extent of canopy or leaf cover, and spectral characteristics of soil (63). Leaf pigments strongly absorb visible light; therefore, reflectance in this region is low overall for healthy vegetation and increases as foliage is stressed (5). Chlorophyll absorbs violet-blue and red light for photosynthesis. Green light is poorly absorbed for photosynthesis; hence, most plants appear green. The changes observed in these visible bands of light may indicate reduced chlorophyll content in the sugar beet canopy, resulting in chlorotic-appearing foliage.
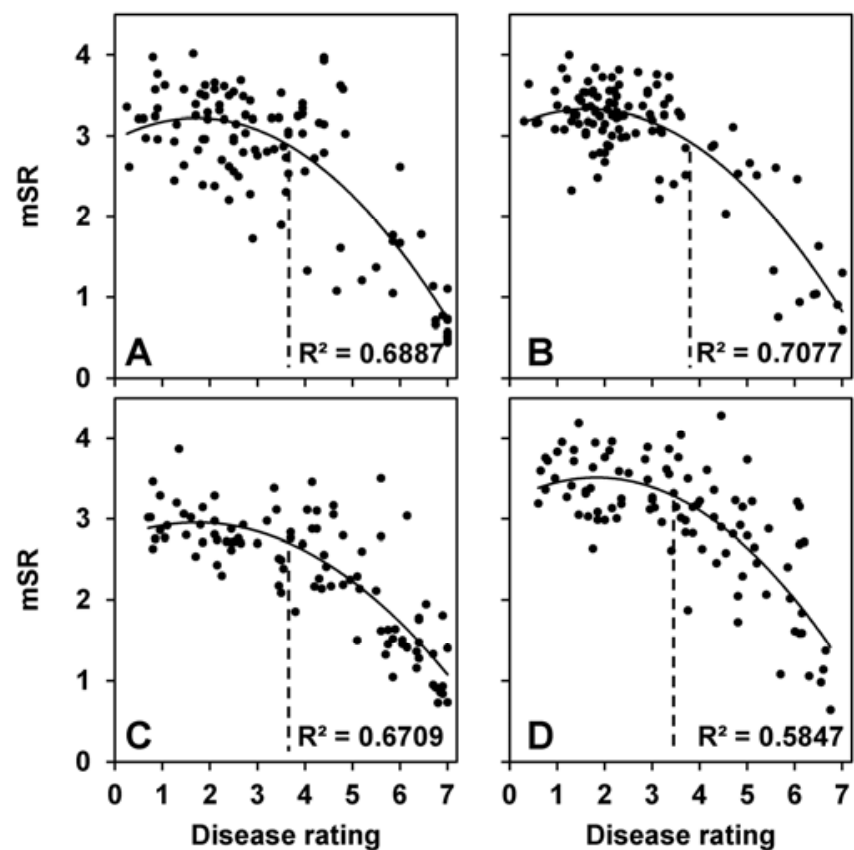

Fig. 2. Modified spectral ratio (mSR) values plotted against Rhizoctonia crown and root rot (RCRR) disease ratings for $A$, a susceptible (S) cultivar in $2008(y=$ $\left.-0.089 x^{2}+0.308 x+2.96\right) ; \mathbf{B}$, a partially resistant (PR) cultivar in $2008\left(y=-0.088 x^{2}+\right.$ $0.289 x+3.09) ; C$, an S cultivar in $2009\left(y=-0.068 x^{2}+0.233 x+2.76\right)$; and $\mathbf{D}$, a PR cultivar in $2009\left(y=-0.087 x^{2}+0.316 x+3.22\right)$ from field trials at the University of Minnesota, Northwest Research and Outreach Center, Crookston. Ratings for RCRR range from 0 to 7 and are based on the amount of rot present on sugar beet tap roots, where $0=$ healthy and $7=100 \%$ rotted and foliage is dead (45). "Tipping points", where mSR values begin to decline, were visually identified and are indicated by dashed lines. 
Near-infrared light is not absorbed by leaf pigments; therefore, reflectance is high in this region and depends on internal leaf structure (29), and changes observed in this region may be due to wilting in the sugar beet canopy. Finally, the middle-infrared reflectance region is associated with water content $(5,8)$. The changes observed in this region may be due to water-stressed sugar beet foliage, which can occur when severe RCRR restricts transpiration. As sugar beet plants die, the canopy begins to collapse, and canopy reflectance becomes a mixture of vegetation and soil background.

Vegetation indices associated with chlorophyll (particularly the OSAVI and mSR) indicated loss of chlorophyll content in foliage as severity of RCRR increased. Although wilting is very likely playing a role in the reflectance responses observed in the various indices and in the aerial imagery, the strong association previously demonstrated between these indices and chlorophyll content suggests that reflectance changes observed in RCRR-infected plots were due, in some part, to reduction in chlorophyll content $(55,62)$. The direct impact of RCRR on chlorophyll content in sugar beet foliage is unknown but could be useful information in refining value of vegetation indices associated with chlorophyll in detection of this disease.
High OSAVI and mSR values suggested that the partially resistant cultivar had higher chlorophyll content than the susceptible cultivar in 2009 (54,62). Overall, the cultivars assessed generally showed similar trends in their regression models, possibly indicating that the OSAVI or mSR can be used to detect RCRR in plants with foliar symptoms of wilt and chlorosis. Our tests were limited to four cultivars, and further experimentation is needed on a wide range of cultivars to determine whether variability among cultivars with various traits (e.g., leaf coloration and plant architecture) could affect results. Also, no studies have been done to correlate the relationship of foliar and root symptoms of RCRR on a wide range of cultivars or germplasm (Lee Panella, personal communication). Perhaps certain cultivars show foliar symptoms earlier or later than those we evaluated in our trials.

Although remote sensing of RCRR is a potential alternative for detecting the disease, rather than visual assessment of roots, it has several drawbacks. The equipment is relatively expensive and requires a careful operator who is familiar with the accompanying software. Measurements must be obtained on clear, sunny days with consistent sun angles (between 10:00 a.m. and 2:00 p.m.) between different dates (16). Research also is needed to determine the sensitivity of remote sensing to detect RCRR compared with

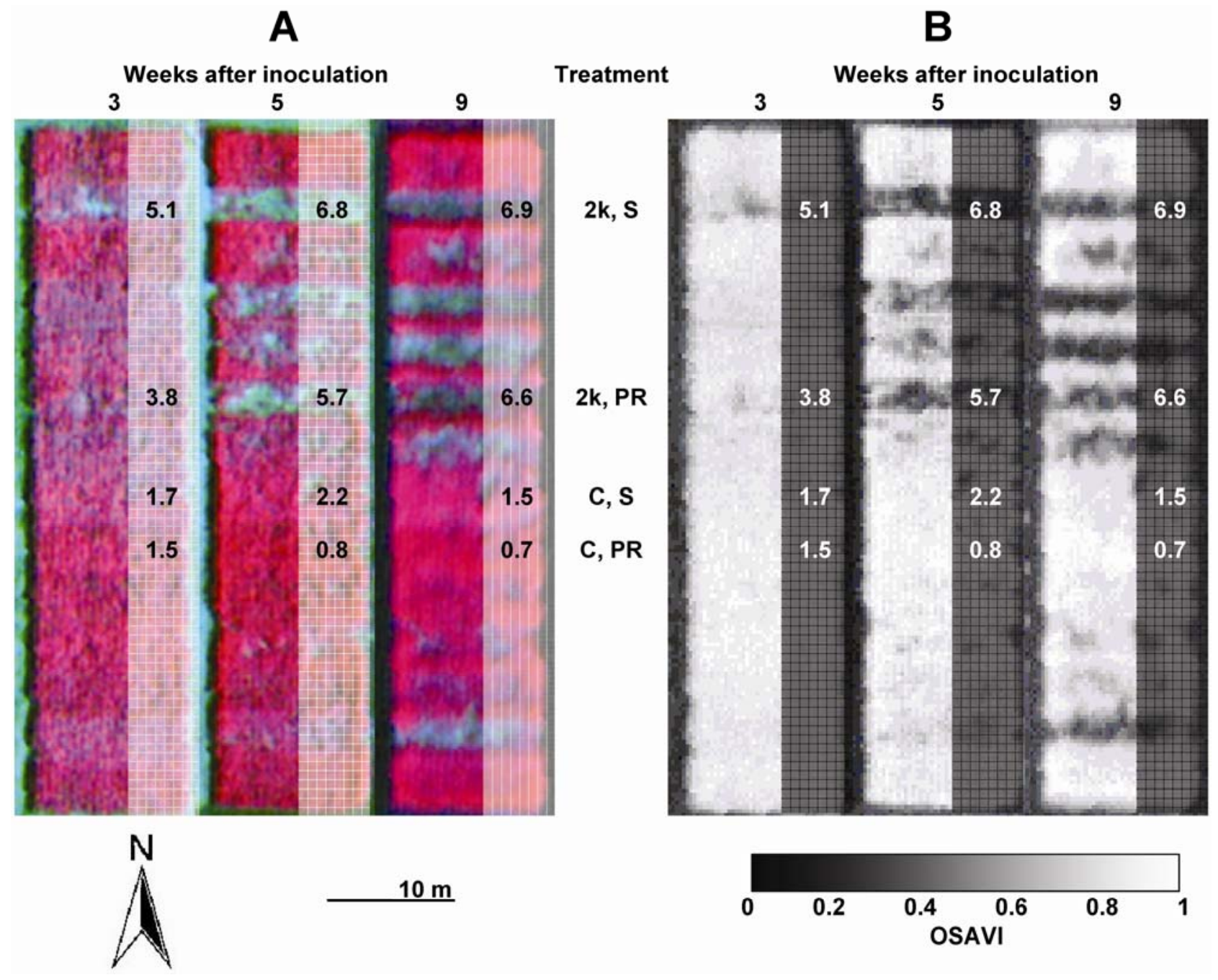

Fig. 3. Sugar beet block (replicate) at the University of Minnesota, Northwest Research and Outreach Center, Crookston shown at 3, 5, and 9 weeks after inoculation (WAI) with Rhizoctonia solani AG 2-2 IIIB as A, color-infrared (CIR) digital imagery at 0.25-m spatial resolution and B, derived optimized soil-adjusted vegetation index (OSAVI) maps. The masked portion of plots (noted on the right side) is where roots were removed for disease assessment, and the remaining area on the left was used for aerial imagery. Rhizoctonia crown and root rot (RCRR) was assessed at each sampling date (10 roots per treatment per date) with a 0 -to-7 rating scale (45), where $0=$ healthy and $7=100 \%$ rotted and foliage is dead. Disease ratings are provided in the masked out area of selected plots. Treatment labels refer to example plots where $S=$ susceptible cultivar and PR = partially resistant cultivar; $2 \mathrm{k}=$ each root inoculated with two corn kernels colonized by Rhizoctonia solani; and C = noninoculated control (all other plots were low to moderate inoculum densities and are not identified). Healthy sugar beet foliage is red in the CIR imagery and light in the OSAVI maps; soil is cyan or black in the CIR imagery and dark in the OSAVI maps. Note that OSAVI values decrease as disease levels increase. 
other maladies that cause sugar beet foliage to become chlorotic and, thereby, complicate and compromise its application. Examples include diseases (Aphanomyces root rot and Cercospora leaf spot), insects (sugar beet root maggot), nutrient deficiencies, and loss of nitrogen from foliage as sugar beet roots mature and store sucrose. Other factors, such as chemical inputs, could also have an impact on reflectance from sugar beet foliage. For example, glyphosate has been shown to reduce chlorophyll content in soybean $(46,51,52)$ but this phenomenon has not been studied on sugar beet in the field.

Detection of RCRR by remote sensing occurs too late for implementation of remedial management measures (i.e., fungicide applications) but aerial imaging may be helpful in identifying areas of possible RCRR that then can be ground truthed. This would be particularly helpful in large fields where it is not practical to walk the entire area looking for potential problems. This approach also could be used to develop risk maps showing areas with potentially high $R$. solani inoculum for future growing seasons. This would allow growers to plan and implement strategic management strategies to control $R$. solani on sugar beet and rotation crops. Furthermore, because it is a nondestructive method, multiple remote sensing-based assessments could be used to determine rate of increase in disease severity or in size of severely infected patches of fields over time. This could be a useful tool for assessing different treatments or the impact of RCRR in varying conditions in future research studies.

Further research is needed to determine whether RCRR has a unique spectral signature on a wide selection of sugar beet cultivars and whether other root or foliar problems (biotic and abiotic) cause a similar response in grower fields. Remote sensing based on thermal infrared emissivity (12) should also be assessed as a potential means for earlier detection of RCRR than reflectance-based remote sensing.

\section{Acknowledgments}

We thank the University of Minnesota, Minnesota Agriculture Experiment Station, and Northwest Research and Outreach Center, Crookston and the Sugarbeet Research and Education Board of Minnesota and North Dakota for funding of this project; J. R. Brantner, J. Nielsen, and student workers (C. Danielson, N. Knutson, J. Reitmeier, C. Solheim, and K. Baird) for assisting with field and laboratory work; and R. Moon for advice on statistical analyses.

\section{Literature Cited}

1. Barnes, E. M., Clarke, T. R., and Richards, S. E. 2000. Coincident detection of crop water stress, nitrogen status and canopy density using ground based multispectral data. In: Proc. 5th Int. Conf. Precision Agric. Bloomington, MN.

2. Barnett, K. A., Sprague, C. L., Kirk, W. W., and Hanson, L. E. 2011. Lack of interaction between glyphosate and fungicide treatments on Rhizoctonia crown and root rot in glyphosate-resistance sugarbeet. J. Sugar Beet Res. 48:1-16.

3. Blackburn, G. A. 1998. Quantifying chlorophylls and carotenoids at leaf and canopy scales: an evaluation of some hyperspectral approaches. Remote Sens. Environ. 66:273-285.

4. Brantner, J. R., and Windels, C. E. 2008. Comparison of inoculation techniques for assessing sugarbeet variety resistance to Rhizoctonia root and crown rot. Sugarbeet Res. Ext. Rep. 38:266-271.

5. Carter, G. A. 1993. Responses of leaf spectral reflectance to plant stress. Am. J. Bot. 80:239-243.

6. Chavez, P., Zorogastua, P., Chuquillanqui, C., Salazar, L. F., Mares, V., and Quiroz, R. 2009. Assessing Potato yellow vein virus (PYVV) infection using remotely sensed data. Int. J. Pest Manage. 55:251-256.

7. Chen, X., Ma, J., Qiao, H., Cheng, D., Xu, Y., and Zhao, Y. 2007. Detecting infestation of take-all disease in wheat using Landsat Thematic Mapper imagery. Int. J. Remote Sens. 28:5183-5189.

8. Cohen, W. B. 1991. Response of vegetation indexes to changes in three measures of leaf water stress. Photogram. Eng. Remote Sens. 57:195-202.

9. Cook, C. G., Escobar, D. E., Everitt, J. H., Cavazos, I., Robinson, A. F., and Davis, M. R. 1999. Utilizing airborne video imagery in kenaf management and production. Ind. Crops Prod. 9:205-210.

10. Engelkes, C. A., and Windels, C. E. 1994. Relationship of plant age, cultivar, and isolate of Rhizoctonia solani AG-2-2 to sugar beet root and crown rot. Plant Dis. 78:685-689.

11. Engelkes, C. A., and Windels, C. E. 1996. Susceptibility of sugar beet and beans to Rhizoctonia solani AG-2-2 IIIB and AG-2-2 IV. Plant Dis. 80:1413-1417

12. Falckenberg, G. 1928. Die Absorptionskonstanten einiger meteorologisch wichtiger Körper für infrarote Wellen. Meteor. Z. 45:334-337.

13. Falkenberg, N. R., Piccinni, G., Cothren, J. T., Leskovar, D. I., and Rush, C. M. 2007. Remote sensing of biotic and abiotic stress for irrigation management of cotton. Agric. Water Manage. 87:23-31.

14. Fredericksen, T. S., and Skelly, J. M. 1994. Relation of visible and physiological foliar injury from ozone exposure in hardwood tree species. (Abstr.) Phytopathology 84:1371.

15. Gitelson, A. A., and Merzlyak, M. N. 1997. Remote estimation of chlorophyll content in higher plant leaves. Int. J. Remote Sens. 18:2691-2697.

16. Guan, J., and Nutter, F. W., Jr. 2001. Factors that affect the quality and quantity of sunlight reflected from alfalfa canopies. Plant Dis. 85:865-874.

17. Hatfield, J. L., and Pinter, P. J. 1993. Remote sensing for crop protection. Crop Prot. 12:403-413.

18. Horsfall, J. G., and Barratt, R. W. 1945. An improved grading system for measuring plant diseases. (Abstr.) Phytopathology 35:655.

19. Inoue, Y. 2003. Synergy of remote sensing and modeling for estimating ecophysiological processes in plant production. Plant Prod. Sci. 6:3-16.

20. Ithurrart, M. E. F., Büttner, G., and Peterson, J. 2004. Rhizoctonia root rot in sugar beet (Beta vulgaris ssp. altissima) - epidemiological aspects in relation to maize (Zea mays) as a host plant. J. Plant Dis. Prot. 111:302-312.

21. Jackson, R. D. 1986. Remote sensing of biotic and abiotic plant stress. Annu. Rev. Phytopathol. 24:265-287.

22. Jacobsen, B. J., Bergman, J., and Eckhoff, J. 1999. Control of Rhizoctonia crown and root rot of sugar beet with fungicides and antagonistic bacteria. Sugar Beet Res. Ext. Rep. 29:278-280.

23. Jensen, J.R. 2005. Introductory Digital Image Processing: A Remote Sensing Perspective, Third Edition. Pearson-Prentice Hall, Upper Saddle River, NJ.

24. Johnsen, A. R., Horgan, B. P., Hulke, B. S., and Cline, V. 2009. Evaluation of remote sensing to measure plant stress in creeping bentgrass (Agrostis stolonifera L.) fairways. Crop Sci. 49:2261-2274.

25. Jordan, C. F. 1969. Derivation of leaf area index from quality of light on the forest floor. Ecology 50:663-666.

26. Khan, M., ed. 2008. Sugarbeet Production Guide. 2008. North Dakota State University and University of Minnesota Cooperative Extension Services. Online publication. www.sbreb.org.

27. Kiewnick, S., Jacobsen, B. J., Braun-Kiewnick, A., Eckhoff, J. L. A., and Bergman, J. W. 2001. Integrated control of Rhizoctonia crown and root rot of sugar beet with fungicides and antagonistic bacteria. Plant Dis. 857:718 722.

28. Kirk, W. W., Wharton, P. S., Schafer, R. L., Tublalam, P., Poindexter, S., Guza, C., Fogg, R., Schlatter, T., Stewart, J., Hubbell, L., and Ruppal, D. 2008. Optimizing fungicide timing for the control of Rhizoctonia crown and root rot of sugar beet using soil temperature and plant growth stages. Plant Dis. 92:1091-1098.

29. Knipling, E. B. 1970. Physical and physiological basis for the reflectance of visible and near-infrared radiation from vegetation. Remote Sens. Environ. $1: 155-159$.

30. Laudien, R., Bareth, G., and Doluschitz, R. 2004. Comparison of remote sensing based analysis of crop diseases by using high resolution multispectral and hyperspectral data - case study: Rhizoctonia solani in sugar beet. Pages 670-676 in: Proc. 12th Int. Conf. Geoinf. University of Gävle, Sweden.

31. Laudien, R., Burcky, K., Doluschitz, R., and Bareth, G. 2006. Establishment of a web-based spectral database for the analysis of hyperspectral data from Rhizoctonia solani-inoculated sugarbeets. Zuckerindustrie 131:164170 .

32. Liu, Z., and Sinclair, J. B., 1991. Isolates of Rhizoctonia solani anastomosis groups 2-2 pathogenic to soybean. Plant Dis. 75:682-687.

33. Malet, P. 1996. Classifying the geometries of canopies from time variations of red and near-infrared reflectance. Remote Sens. Environ. 56:164-171.

34. Matheron, M. E., Wright, C. G., and Porchas, M. 1998. Resistance to Phytophthora citrophthora and $P$. parasitica and nursery characteristics of several citrus rootstocks. Plant Dis. 82:1217-1225.

35. Meroni, M., Rossini, M., Guanter, L., Alonso, L., Rascher, U., Colombo, R. and Moreno, J. 2009. Remote sensing of solar-induced chlorophyll fluorescence: review of methods and applications. Remote Sens. Environ. 113:2037-2051

36. Merton, R. N., and Harvey, L. E. 1997. Analysis of seasonal changes in Jasper Ridge vegetation biochemistry and biophysiology using multitemporal hyperspectral data. Am. Soc. Photogramm. Remote Sens. Conf. Seattle.

37. Naidu, V. D., Rao, B. S., and Murty, P. S. S. 1981. Influence of sheath blight infection on the levels of chlorophyll and $14 \mathrm{CO}_{2}$ uptake in rice. Indian Phytopathol. 34:30-33.

38. Nilsson, H. E. 1995. Remote sensing and image analysis in plant pathology. Annu. Rev. Phytopathol. 33:489-527.

39. Nofal, M. A., Sahab, A. F., Diab, M. M, and Morsy, A. A. 1985. Response of broad bean plants infected with root-rot fungi to Fuli-Fertile application. Egypt. J. Phytopathol. 14:67-74.

40. North Dakota Agricultural Weather Network. 1993-2009. Online publication. http://ndawn.ndsu.nodak.edu.

41. Nutter, F. W., Jr., Gleason, M. L., Jenco, J. H., and Christians, N. C. 1993. Assessing the accuracy, intra-rater repeatability, and inter-rater reliability of disease assessment systems. Phytopathology 83:806-812. 
42. Nutter, F. W., Jr., Guan, J., Gotlieb, A. R., Rhodes, L. H., Grau, C. R., and Sulc, R. M. 2002. Quantifying alfalfa yield losses caused by foliar diseases in Iowa, Ohio, Wisconsin, and Vermont. Plant Dis. 86:269-277.

43. Nutter, F. W., Jr., and Schultz, P. M. 1995. Improving the accuracy and precision of disease assessments: selection of methods and use of computeraided training programs. Can. J. Plant Pathol. 17:174-184.

44. Omer, M., Lock, J. C., and Frantz, J. M. 2007. Using leaf temperature as a nondestructive procedure to detect root rot stress in geranium. HortTechnology 17:532-536.

45. Panella, L. 1998. Screening and utilizing Beta genetic resources with resistance to Rhizoctonia root rot and Cercospora leaf spot in a sugar beet breeding programme. Pages 62-72 in: 4th Int. Beta Genet. Resour. Workshop World Beta Network Conf. L. Frese, L. Panella, H. M. Srivastava, and W. Lange, eds. Aegean Agric. Res. Inst. Izmir, Turkey. Int. Crop Network Ser. No. 12, International Plant Genetic Resources Institute, Rome.

46. Pline, W. A., Wu, J., and Hatzios, K. K. 1999. Effects of temperature and chemical additives on the response of transgenic herbicide-resistant soybeans to glufosinate and glyphosate applications. Pestic. Biochem. Physiol. 65:119-131.

47. Pozdnyakova, L., Oudemans, P. V., Hughes, M. G., and Giménez, D. 2002. Estimation of spatial and spectral properties of Phytophthora root rot and its effects on cranberry yield. Comput. Electron. Agric. 37:57-70.

48. Qin, Z., and Zhang, M. 2005. Detection of rice sheath blight for in-season disease management using multispectral remote sensing. Int. J. Appl. Earth Obs. Geoinf. 7:115-128.

49. Raikes, C., and Burpee, L. L. 1998. Use of multispectral radiometry for assessment of Rhizoctonia blight in creeping bentgrass. Phytopathology 88:446-449.

50. R Development Core Team. 2009. R: A Language and Environment for Statistical Computing. R Foundation for Statistical Computing, Vienna. http://www.R-project.org.

51. Reddy, K. N., Hoagland, R. E., and Zablotowicz, R. M. 2000. Effect of glyphosate on growth, chlorophyll, and nodulation in glyphosate-resistant and susceptible soybean (Glycine max) varieties. J. New Seeds 2:37-52.

52. Reddy, K. N., and Zablotowicz, R. M. 2003. Glyphosate-resistant soybean response to various salts of glyphosate and glyphosate accumulation in soybean nodules. Weed Sci. 51:496-502.

53. Reynolds, G. J., Windels, C. E., MacRae, I. V., and Laguette, S. 2009. Hyperspectral remote sensing for detection of Rhizoctonia crown and root rot in sugar beet. (Abstr.) Phytopathology 99:S108.

54. Rondeaux, G., Steven, M., and Baret, F. 1996. Optimization of soil-adjusted vegetation indices. Remote Sens. Environ. 55:95-107.

55. Rouse, J. W., Haas, R. H., Schell, J. A., and Deering, D. W. 1973. Monitoring vegetation systems in the Great Plains with ERTS. Pages 309-317 in: Third ERTS Symp. NASA SP-351 I.

56. Ruppel, E. G, Schneider, C. L., Hecker, R. J., and Hogaboam, G. J. 1979. Creating epiphytotics of Rhizoctonia root rot and evaluating for resistance to Rhizoctonia solani in sugarbeet field plots. Plant Dis. Rep. 63:518-522.

57. Rush, C. M., and Winter, S. R. 1990. Influence of previous crops on Rhizoctonia root and crown rot of sugar beet. Plant Dis. 74:421-425.

58. Schuster, M. L., and Harris, L. 1960. Incidence of Rhizoctonia crown rot of sugar beets in irrigated crop rotation. J. Am. Soc. Sugar Beet Technol. 11:128-136.

59. Seelig, H. D., Hoehn, A., Stodieck, L. S., Klaus, D. M., Adams, W. W., III, and Emery, W. K. 2008. Relations of remote sensing leaf water indices to leaf water thickness in cowpea, bean, and sugarbeet plants. Remote Sens. Environ. 112:445-455.

60. Sherwood, R. T., Berg, C. C., Hoover, M. R., and Zeiders, K. E. 1983. Illusions in visual assessment of Stagonospora leaf spot of orchardgrass. Phytopathology 73:173-177.

61. Shokes, F. M., Berger, R. D., Smith, D. H., and Rasp, J. M. 1987. Reliability of disease assessment procedures: a case study with late leafspot of peanut. Oléagineux 42:245-251.

62. Sims, D. A., and Gamon, J. A. 2003. Estimation of vegetation water content and photosynthetic tissue area from spectral reflectance: a comparison of indices based on liquid water and chlorophyll absorption features. Remote Sens. Environ. 84:526-537.

63. Spanner, M. A., Pierce, L. L., Peterson, D. L., and Running, S. W. 1990 Remote sensing of temperate coniferous forest leaf area index-the influence of canopy closure, understory vegetation and background reflectance. Int. J. Remote Sens. 11:95-111.

64. Stachler, J. M., Carlson, A. L., Luecke, J. L., Boetel, M. A., and Khan, F. R. 2010. Survey of weed control and production practices on sugarbeet in Minnesota and North Dakota in 2009. Sugarbeet Res. Ext. Rep. 40:39-60.

65. Steddom, K., Bredehoeft, M. W., Khan, M., and Rush, C. M. 2005. Comparison of visual and multispectral radiometric disease evaluations of Cercospora leaf spot of sugar beet. Plant Dis. 89:153-158.

66. Steddom, K., Heidel, G., Jones, D., and Rush, C. M. 2003. Remote detection of rhizomania in sugar beets. Phytopathology 93:720-726.

67. Stump, W. L., Franc, G. D., Miller, S. D., and Wilson, R. G. 2002. Azoxystrobin and post emergence herbicide combination for Rhizoctonia and weed management. J. Sugar Beet Res. 39:37-58.

68. Thenkabail, P. S., Smith, R. B., and De Pauw, E. 2002. Evaluation of narrowband and broadband vegetation indices for determining optimal hyperspectral wavebands for agricultural crop characterization. Photogram. Eng. Remote Sens. 68:607-621.

69. United States Department of Agriculture (USDA). 1993-2009. National Agricultural Statistics, USDA. Online publication. http://www.nass usda.gov.

70. Wang, D., Kurle, J. E., Estevez de Jensen, C., and Percich, J. A. 2004 Radiometric assessment of tillage and seed treatment effect on soybean root rot caused by Fusarium spp. in central Minnesota. Plant Soil 258:319-331.

71. West, J. S., Bravo, C., Oberti, R., Lemaire, D., Moshou, D., and McCartney, H. A. 2003. The potential of optical canopy measurement for targeted control of field diseases. Annu. Rev. Phytopathol. 41:593-614.

72. Windels, C. E., and Brantner, J. R. 2005. Early-season application of azoxystrobin to sugarbeet for control of Rhizoctonia solani AG-4 and AG 2-2. J. Sugar Beet Res. 42:1-17.

73. Windels, C. E., and Brantner, J. R. 2009. Prevalence and distribution of Rhizoctonia solani AG 2-2 ISGs in sugar beet-growing areas of Minnesota and North Dakota with different crop rotations. (Abstr.) Phytopathology 99:S15.

74. Windels, C. E., and Brantner, J. R. 2011. Aggressiveness of Rhizoctonia solani AG 2-2 on sugar beet and rotation crops. J. Sugar Beet Res. 48:92-93.

75. Windels, C. E., Jacobsen, B. J., and Harveson, R. M. 2009. Rhizoctonia crown and root rot. Pages 33-36 in: Compendium of Beet Diseases and Pests. R. M. Harveson, L. E. Hanson, and G. L. Hein, eds. American Phytopathological Society Press, St. Paul, MN. 